\title{
Relationship between Chemical Structure of Caking Additives Produced from Low Rank Coals and Coke Strength
}

\author{
Naoto SAKIMOTO, ${ }^{1)}$ Toshimasa TAKANOHASHI, ${ }^{1) *}$ Yasuyuki HARADA ${ }^{2)}$ and Hidekazu FUJIMOTO ${ }^{3)}$ \\ 1) National Institute of Advanced Industrial Science and Technology (AIST), 16-1 Onogawa, Tsukuba, Ibaraki, $305-8569$ \\ Japan. 2) Mitsubishi Chemical Corporation, 1, Bannosu-cho, Sakaide, Kagawa, 762-8510 Japan. \\ 3) JFE Steel Corporation, 1-1, Ougijima, Kawasaki, Kanagawa, 210-0868 Japan.
}

(Received on April 1, 2014; accepted on Octorber 1, 2014; originally published in Tetsu-to-Hagané, Vol. 100, 2014, No. 2, pp. 134-139)

\begin{abstract}
Coke strength can be enhanced by adding HyperCoals (HPC). HPC can be produced from different rank of coals including low rank coals. The aim of this study is to investigate and evaluate the usability of HPC from low rank coals as caking additive. ${ }^{1} \mathrm{H}-\mathrm{NMR}$, solid state ${ }^{13} \mathrm{C}-\mathrm{NMR}$, and elemental analysis were carried out to investigate the molecular structure of HPC prepared from low rank coals. The results showed that the number of aromatic rings in unit structure increased from 1-2 in original coals to 2-3 in HPCs extracted at $633 \mathrm{~K}$. Effect of extraction temperature was also investigated and it was found that ratio of 3 aromatic rings increased in HPC extracted at $673 \mathrm{~K}$, in comparison to HPC extracted at $633 \mathrm{~K}$. The strength of cokes produced by adding HPC was directly a function of number of aromatic rings in the HPC and increased with increasing number of rings.
\end{abstract}

KEY WORDS: HyperCoal (HPC); low-rank coal; coke; structural analysis.

\section{Introduction}

It is necessary to use caking coals to produce high quality coke. However, caking coal is expensive and its reserve amount is small. Therefore, a technology without reducing the quality and with increasing the blending ratio of the nonand/or slightly caking coals is desired. Generally, coke strength decreases with increasing the ratio of non- and/or slightly caking coals, however, it is possible to recover or improve the strength by adding HyperCoal (HPC) produced by the solvent extraction. ${ }^{1-3)}$ Takanohashi et al. ${ }^{2)}$ reported that coke strength increased by producing HPC from a caking coal and adding it to blending coals including 35 mass \% of non- and/or slightly caking coal. Shishido et al. ${ }^{3)}$ reported that the higher ratio of non- and/or slightly caking coals were blended, the more blending effect on the coke strength improved. Thus, adding HPC is effective to improve the strength of coke blended with non- and/or slightly caking coals.

On the other hand, since HPC can be produced from various coals including lignite and sub-bituminous ${ }^{4)}$ coal, it is expected to produce HPC from cost-effective low-rank coals. Koyano et $a l .{ }^{5)}$ reported that when adding various poly-aromatic hydrocarbons to coals as caking additive, the coke strength increased in the cases of more than 4 aromatic rings and the effect enhanced with increasing the number of aromatic rings. Also comparing between the poly-aromatics with the same ring size, the coke strength improved more

* Corresponding author: E-mail: toshi-takanohashi@aist.go.jp DOI: http://dx.doi.org/10.2355/isijinternational.54.2426 with peri-type compounds than cata-type ones. ${ }^{5)}$

It is previously reported that the average number of aromatic rings in low-rank coals is around 1-2.6) If the number of aromatic rings in HPC produced from low-rank coals is nearly equal (1-2 rings), the improvement of coke strength may not be expected, although it should not be easily compared with model compounds since their polarity or molecular weight are different. Moreover, since low-rank coals contain a large amount of oxygen functional groups, ${ }^{7)}$ the plasticity of blending coals may significantly decrease. The details on the molecular structure of HPC and the mechanism of its effect have not been clarified so far.

In the current work, structural analysis of HPC produced from low-rank coals on various extraction conditions was performed in order to clarify its molecular structure and characteristics. By adding those HPC to slightly caking coal, the effect on coke strength and its relationship to molecular structure was investigated.

\section{Experiments}

\subsection{Coal Sample and Sample Preparation}

Two Indonesian low-rank coals, Pasir (Pa) sub-bituminous coal and Mulia (Mu) lignite coal, were used to produce HPC by solvent extraction. One Chinese coal, Kouryusho (KRS) slightly caking coal, was used as a standard coal for cokemaking. Low-rank coals were ground to under $0.15 \mathrm{~mm}$ and the standard coal was ground to $0.42-1.0 \mathrm{~mm}, 0.15-0.42 \mathrm{~mm}$ and under $0.15 \mathrm{~mm}$, respectively. Ground coals were dried in vacuo at $353 \mathrm{~K}$ for 12 hours. Ultimate analysis and ash content of coal samples are shown in Table 1. 
Table 1. Ultimate analysis of coal samples.

\begin{tabular}{|c|c|c|c|c|c|c|c|c|}
\hline & \multicolumn{5}{|c|}{ mass $\%$, daf } & \multirow{2}{*}{$\mathrm{H} / \mathrm{C}$} & \multirow{2}{*}{$\mathrm{O} / \mathrm{C}$} & \multirow{2}{*}{$\begin{array}{c}\text { Ash } \\
\operatorname{mass} \%, \mathrm{db}\end{array}$} \\
\hline & $\mathrm{C}$ & $\mathrm{H}$ & $\mathrm{N}$ & $\mathrm{S}$ & $\mathrm{O}$ (diff.) & & & \\
\hline Mulia & 57.2 & 5.6 & 0.8 & 0.1 & 36.3 & 1.17 & 0.48 & 2.6 \\
\hline Pasir & 66.0 & 5.4 & 1.2 & 0.2 & 27.2 & 0.98 & 0.31 & 5.5 \\
\hline KRS & 80.0 & 5.2 & 1.6 & 0.4 & 12.8 & 0.78 & 0.12 & 7.7 \\
\hline
\end{tabular}

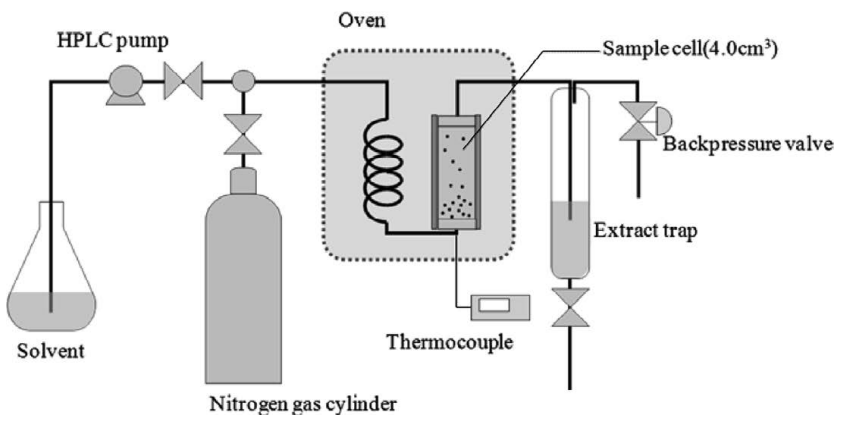

Fig. 1. Schematic of semi-flowing extractor.

\subsection{Solvent Extraction}

A semi-flowing extractor was used for thermal solvent extraction. Schematic of extraction apparatus is shown in Fig. 1. Around $2.5 \mathrm{~g}$ of coal was set on a stainless filter in an extractor, and purged with $\mathrm{N}_{2}$ of $1.0 \mathrm{MPa}$ initial pressure. The sample cell was filled with 1-methylnaphthelene (1MN) and heated up to the extraction temperature $(633 \mathrm{~K}$ or $673 \mathrm{~K})$ and $1 \mathrm{MN}$ was continuously injected into the system at a flow rate of $0.4 \mathrm{ml} / \mathrm{min}$ for $60 \mathrm{~min}$. The extract solution was dissolved into 40 times volume of hexane and separated into soluble part (1MN and hexane soluble part) and insoluble one. The insoluble part was dried in vacuo at $353 \mathrm{~K}$ for 12 hours. This dried insoluble part was defined as HPC. Henceforward, HPC produced from low-rank coals was represented as $\mathrm{Mu}-360, \mathrm{Mu}-400, \mathrm{~Pa}-360$ and $\mathrm{Pa}-400$, respectively (e.g. Mu-360 means HPC produced from Mulia coal at $633 \mathrm{~K}$ ). Additionally, for comparison, HPC (BIT-380) produced from a bituminous coal by using bench scale HPC plant $(0.1 \mathrm{t} / \mathrm{d})$ was used for HPC sample.

The extract obtained from the ultrasonic extraction with $\mathrm{CS}_{2}$ /Pyridine mixed solvent (1:1 by volume) at room temperature was also used, in order to examine possibility of chemical reactions during thermal solvent extraction described above. These room-temperature extracts produced from $\mathrm{Mu}$ and $\mathrm{Pa}$ were represented as $\mathrm{Mu}-\mathrm{RT}$ and $\mathrm{Pa}-\mathrm{RT}$, respectively.

Ultimate analysis of these extracts is shown in Table 2.

\subsection{Liquid State ${ }^{\mathbf{1}} \mathrm{H}-\mathrm{NMR}$ Measurement}

The aromaticity $\left(f_{a}\right)$ and hydrogen type distribution were measured by liquid state ${ }^{1} \mathrm{H}-\mathrm{NMR}$ (Lambda500, JEOL). $\mathrm{CS}_{2} /$ pyridine-d5 (1:1 by volume) was used for solvent. Hydrogen types were classified to 4 types. The one was aromatic hydrogen $\left(\mathrm{H}_{\mathrm{ar}}, 6.0-10.0 \mathrm{ppm}\right)$. The others were aliphatic hydrogen, $\mathrm{H}_{\alpha}(2.0-5.0 \mathrm{ppm}), \mathrm{H}_{\beta}(1.1-2.0 \mathrm{ppm})$ and $\mathrm{H}_{\gamma}(0.2-1.1 \mathrm{ppm})$.

The aromatic carbon ratio $\left(f_{a}\right)$ and hydrogen type distribution were measured by liquid state ${ }^{1} \mathrm{H}-\mathrm{NMR}$ (Lambda500, JEOL). $\mathrm{CS}_{2} /$ pyridine-d5 (1:1 by volume) was used for sol-
Table 2. Ultimate analysis of extracts.

\begin{tabular}{|c|c|c|c|c|c|c|c|}
\hline \multirow{2}{*}{ Sample } & \multicolumn{5}{|c|}{ mass $\%$, daf } & \multirow{2}{*}{$\mathrm{H} / \mathrm{C}$} & \multirow{2}{*}{$\mathrm{O} / \mathrm{C}$} \\
\hline & $\mathrm{C}$ & $\mathrm{H}$ & $\mathrm{N}$ & $\mathrm{S}$ & $\mathrm{O}$ (diff.) & & \\
\hline BIT-380 & 86.2 & 5.9 & 1.8 & 0.6 & 5.5 & 0.82 & 0.05 \\
\hline $\mathrm{Mu}-\mathrm{RT}$ & 72.7 & 7.4 & 0.8 & 0.1 & 19.0 & 1.22 & 0.20 \\
\hline $\mathrm{Mu}-360$ & 76.0 & 5.5 & 0.9 & 0.3 & 17.3 & 0.87 & 0.17 \\
\hline $\mathrm{Mu}-400$ & 78.7 & 5.3 & 1.3 & 0.5 & 14.2 & 0.81 & 0.14 \\
\hline $\mathrm{Pa}-\mathrm{RT}$ & 71.1 & 7.0 & 1.2 & 0.2 & 20.5 & 1.18 & 0.22 \\
\hline Pa-360 & 77.7 & 5.5 & 1.3 & 0.3 & 15.2 & 0.85 & 0.15 \\
\hline $\mathrm{Pa}-400$ & 79.2 & 5.3 & 1.6 & 0.5 & 13.4 & 0.80 & 0.13 \\
\hline
\end{tabular}

vent. Hydrogen types were classified to 4 types, aromatic hydrogen; $\mathrm{H}_{\mathrm{ar}}(6.0-10.0 \mathrm{ppm})$, aliphatic hydrogen attached on carbon at $\alpha$ position; $\mathrm{H}_{\alpha}(2.0-5.0 \mathrm{ppm})$, at $\beta$ position; $\mathrm{H}_{\beta}$ (1.1-2.0 ppm) and at $\gamma$ position; $\mathrm{H}_{\gamma}(0.2-1.1 \mathrm{ppm})$.

\subsection{Solid State ${ }^{13}$ C-NMR Measurement}

Oxygen type distribution and $f_{a}$ were measured by solid state ${ }^{13} \mathrm{C}-\mathrm{NMR}$ (CMX-300, JEOL). Oxygen type distribution for room-temperature extract was assumed as similar to the values for original coal, because it was not solid state, like a pitch. Classification of the ${ }^{13} \mathrm{C}-\mathrm{NMR}$ spectrum was determined by reference to the literature; ${ }^{8)}$ aliphatic carbon $\left(\mathrm{C}_{\mathrm{ali}}, 0-93 \mathrm{ppm}\right)$ and aromatic one $\left(\mathrm{C}_{\mathrm{ar}}, 93-171 \mathrm{ppm}\right)$.

In this paper, it was assumed that there were three oxygen types, phenolic hydroxyl group (148-171 ppm), carboxyl group (171-200 ppm) and ether. The oxygen content of ether type was calculated from the total oxygen content minus the phenolic hydroxyl and carboxyl ones.

\subsection{Coke Strength Measurement}

Coke sample was produced from KRS by adding HPC. The adding HPC amount was 3 mass \%. In case adding HPC, to avoid the effect of coal particle size distribution, under $0.15 \mathrm{~mm}$ of coal was replaced by HPC. Particle size distribution of coal for cokemaking is shown in Table 3.

Schematic of cokemaking and strength measurement is shown in Fig. 2. Approximately $5 \mathrm{~g}$ blended coal sample was put into baking vessel. Bulk density of blended coal was $800 \mathrm{~kg} / \mathrm{m}^{3}$. Packed sample was carbonized under a weight load of $6.24 \mathrm{kPa}(200 \mathrm{~g})$ and $\mathrm{N}_{2}$ flow by muffle oven (FO410, Yamato). The oven was heated up from room temperature to $1273 \mathrm{~K}$ at $3 \mathrm{~K} / \mathrm{min}$ heating rate. Once temperature reached $1273 \mathrm{~K}$, the sample was held for $30 \mathrm{~min}$ and cooled down to $473 \mathrm{~K}$ in $\mathrm{N}_{2}$ flow. After cool down, the coke was taken out from the baking vessel and was used for strength measurement. Generally three coke pieces were produced in one condition.

The coke compressive load was measured using an Auto Graph (AG-IS-5kN, SHIMADZU). Coke indirect tensile strength was calculated by Eq. (1). ${ }^{9)}$

$$
S=\frac{4 \cdot P}{\pi \cdot r \cdot l}
$$

In here, $S$ is coke indirect tensile strength ( $\mathrm{MPa}), P$ is failure load $(\mathrm{N}), r$ is sample radius $(\mathrm{mm}), l$ is sample thickness (mm). $r$ and $l$ of produced coke were approximately $8.7 \mathrm{~mm}$ and $11.0 \mathrm{~mm}$, respectively. The strength data were plotted 
Table 3. Grain size distribution of coal for cokemaking.

\begin{tabular}{cccc}
\hline Sample & Particle size & No additive & $3 \%$ additive \\
\hline \multirow{2}{*}{ KRS } & $0.42-1.0 \mathrm{~mm}$ & 33 mass $\%$ & 33 mass $\%$ \\
& $0.15-0.42 \mathrm{~mm}$ & 33 mass $\%$ & 33 mass $\%$ \\
& Under $0.15 \mathrm{~mm}$ & 34 mass $\%$ & 31 mass $\%$ \\
\hline \multirow{2}{*}{ Additive } & Under $0.15 \mathrm{~mm}$ & 0 mass $\%$ & 3 mass $\%$ \\
\hline
\end{tabular}

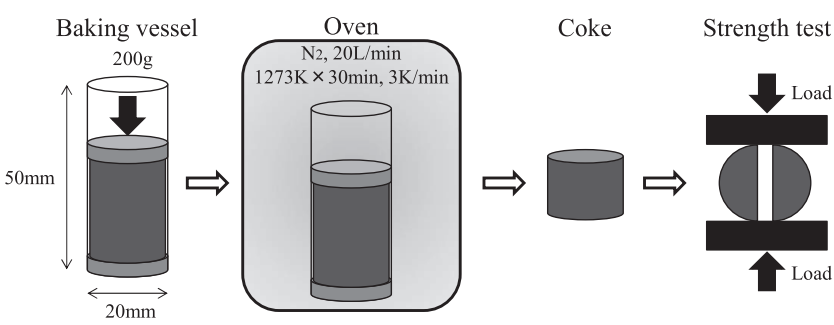

Fig. 2. Schematic of cokemaking and strength measurement.

on a Weibull plot, and the value corresponding to the scale parameter was defined as the coke representative strength.

\section{Results and Discussion}

\subsection{Extraction Yield}

Yields of extract, residue and gas + hexane soluble are shown in Fig. 3. Here, the yield of gas + hexane soluble is the value of coal organic components minus yields of residue and extract. In comparison between the room-temperature extraction and the $633 \mathrm{~K}$ extraction, HPC (extract) yield increased from $8.1 \%$ to $20.0 \%$ for $\mathrm{Pa}$, from $13.6 \%$ to $18.0 \%$ for $\mathrm{Mu}$. From the result of ultimate analysis in Table 2, the $\mathrm{H} / \mathrm{C}$ atomic ratio decreased from 1.18 to 0.85 for $\mathrm{Pa}$, from 1.22 to 0.87 for $\mathrm{Mu}$ and came close to the value of BIT-380 produced from bituminous coal $(\mathrm{H} / \mathrm{C}: 0.82)$. The $\mathrm{O} / \mathrm{C}$ atomic ratio also decreased from 0.22 to 0.15 for $\mathrm{Pa}$, from 0.20 to 0.17 for $\mathrm{Mu}$ and slightly approached to the value of BIT$380(\mathrm{O} / \mathrm{C}: 0.05)$. In addition to the above results, the production of a significant amount of gas and hexane soluble indicates the occurrence of chemical reaction such as thermal decomposition in both coals at $633 \mathrm{~K}$ extraction.

Furthermore, at $673 \mathrm{~K}$ extraction, HPC yield increased to $26.4 \%$ for $\mathrm{Pa}$, and to $20.0 \%$ for $\mathrm{Mu}$. Also $\mathrm{H} / \mathrm{C}$ and $\mathrm{O} / \mathrm{C}$ decreased to 0.80 and 0.13 for $\mathrm{Pa}, 0.81$ and 0.14 for $\mathrm{Mu}$, which means $\mathrm{H} / \mathrm{C}$ became almost the same as the value of BIT-380, and $\mathrm{O} / \mathrm{C}$ also came closer to it. From these results, it was expected that further chemical reaction has progressed at $673 \mathrm{~K}$ extraction.

\subsection{Structural Analysis}

\subsection{1. ${ }^{1} \mathrm{H}-\mathrm{NMR}$ Spectrum}

Table 4 shows hydrogen type distribution and the number of hydrogen type per 100 carbons. In the $633 \mathrm{~K}$ extraction, $\mathrm{H}_{\mathrm{ar}}$ fraction significantly increased from $15.7 \%$ to $43.9 \%$ for $\mathrm{Pa}$, from $18.0 \%$ to $42.7 \%$ for $\mathrm{Mu}$, in comparison with roomtemperature extraction. On the other hand, $\mathrm{H}_{\beta}$ and $\mathrm{H}_{\gamma}$ fraction showed a tendency to decrease. From the above results, it is indicated that as chemical reaction such as thermal decomposition progressed at $633 \mathrm{~K}$ extraction, aromatic hydrogen $\left(\mathrm{H}_{\mathrm{ar}}\right)$ increased and conversely aliphatic hydrogen

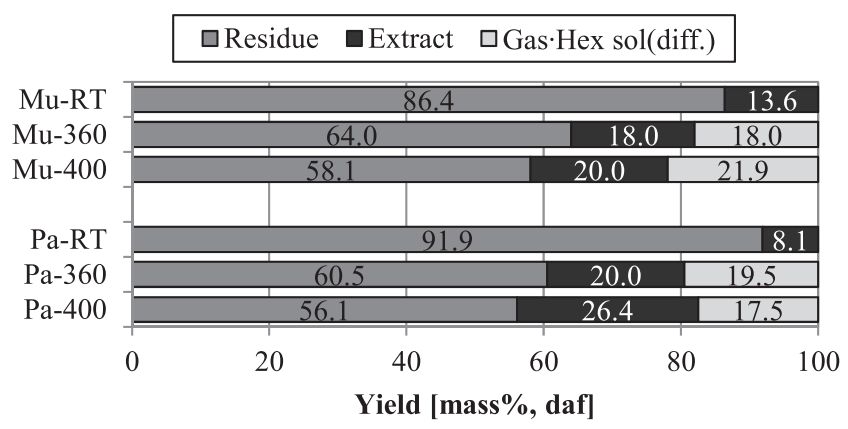

Fig. 3. Results of solvent extractions at room temperature, $633 \mathrm{~K}$ and $673 \mathrm{~K}$.

Table 4. Hydrogen type distribution and number of hydrogen type per 100 carbons.

\begin{tabular}{|c|c|c|c|c|c|c|c|c|}
\hline \multirow{2}{*}{ Sample } & \multicolumn{4}{|c|}{ Hydrogen fraction $[\%]$} & \multicolumn{4}{|c|}{$\begin{array}{c}\text { Number of Hydrogen } \\
\text { [-/100 Carbons }]\end{array}$} \\
\hline & $\mathrm{H}_{\mathrm{ar}}$ & $\mathrm{H}_{\alpha}$ & $\mathrm{H}_{\beta}$ & $\mathrm{H}_{\gamma}$ & $\mathrm{H}_{\mathrm{ar}}$ & $\mathrm{H}_{\alpha}$ & $\mathrm{H}_{\beta}$ & $\mathrm{H}_{\gamma}$ \\
\hline BIT-380 & 40.6 & 29.1 & 24.4 & 6.0 & 33.4 & 24.0 & 20.1 & 4.9 \\
\hline Mu-RT & 18.0 & 19.8 & 41.7 & 20.6 & 6.1 & 26.6 & 61.6 & 28.7 \\
\hline $\mathrm{Mu}-360$ & 42.7 & 15.6 & 33.9 & 7.8 & 28.3 & 16.0 & 34.7 & 8.0 \\
\hline $\mathrm{Mu}-400$ & 37.4 & 20.4 & 32.9 & 9.3 & 30.4 & 16.6 & 26.7 & 7.6 \\
\hline $\mathrm{Pa}-\mathrm{RT}$ & 15.7 & 19.3 & 44.4 & 20.7 & 17.8 & 24.3 & 51.5 & 25.3 \\
\hline Pa-360 & 43.9 & 18.1 & 30.3 & 7.6 & 29.5 & 18.0 & 30.2 & 7.6 \\
\hline $\mathrm{Pa}-400$ & 41.9 & 23.2 & 27.9 & 7.1 & 33.6 & 18.6 & 22.4 & 5.7 \\
\hline
\end{tabular}

$\left(\mathrm{H}_{\beta}\right.$ and $\left.\mathrm{H}_{\gamma}\right)$ decreased.

From the number of hydrogen type per 100 carbons, at $673 \mathrm{~K}$ extraction $\mathrm{H}_{\mathrm{ar}}$ increased to 33.6 for $\mathrm{Pa}$ and 30.4 for $\mathrm{Mu}$, and $\mathrm{H}_{\beta}$ and $\mathrm{H}_{\gamma}$ fraction decreased.

\subsection{2. ${ }^{13} \mathrm{C}-\mathrm{NMR}$ Spectrum}

Figures 4 and 5 shows solid state ${ }^{13} \mathrm{C}$-NMR spectrum of $\mathrm{Pa}$ and $\mathrm{Mu}$. The results were standardized to be the same spectrum area. Comparing the spectrum of raw coal with that of $633 \mathrm{~K}$ extraction, it is identified that for both coals, the aromatic carbon ratio increased and the aliphatic carbon decreased at $633 \mathrm{~K}$ extraction. In $673 \mathrm{~K}$ extraction, this increase/decrease progressed more and the spectrum came close to that of BIT-380.

Table 5 shows the oxygen type distribution and the number of oxygen type per 100 carbons. The number of oxygen per 100 carbons in carboxyl group decreased for both coals at $633 \mathrm{~K}$ extraction. It became 4.4 from 7.4 for $\mathrm{Pa}, 4.9$ from 5.4 for $\mathrm{Mu}$. Those values decreased more at $677 \mathrm{~K}$ extraction, to 2.5 for $\mathrm{Pa}$ and to 2.6 for $\mathrm{Mu}$. The above results indicate that the thermal solvent extraction caused decarboxylation reaction. From the number of oxygen type per 100 carbons, the phenolic hydroxyl group of $\mathrm{Mu}$ has not decreased so much even at $677 \mathrm{~K}$ extraction, but that of $\mathrm{Pa}$ slightly decreased according to thermal solvent extraction. About the ether oxygen, for both coals, the number per 100 carbons decreased at $633 \mathrm{~K}$ extraction but had no change at $677 \mathrm{~K}$. From the above results, it is clarified that the decrease of $\mathrm{O} / \mathrm{C}$ by thermal solvent extraction was mainly caused by decarboxylation reaction. 

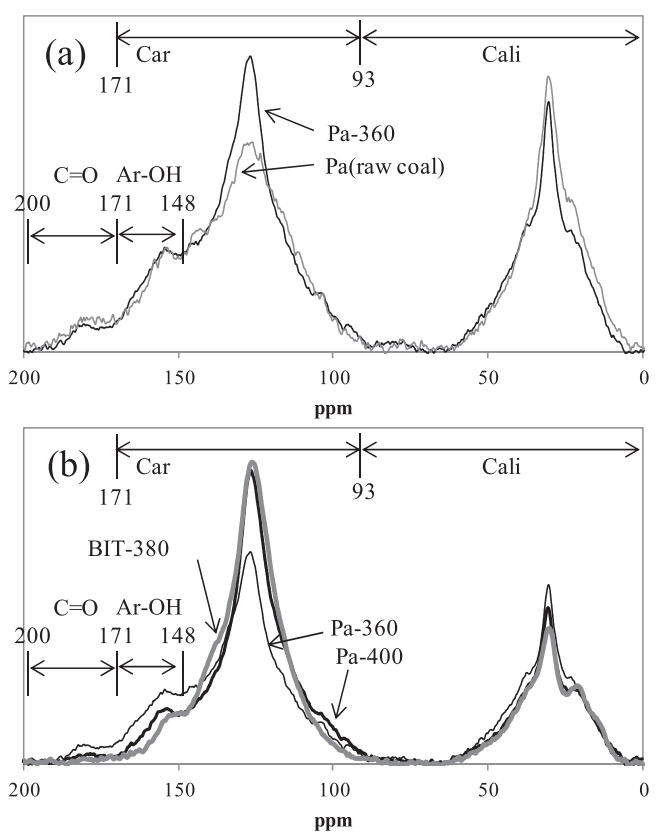

Fig. 4. Solid state ${ }^{13} \mathrm{C}-\mathrm{NMR}$ spectrum (a)comparison of Pasir coal with Pa-360 (b)comparison of BIT-380, Pa-360 and Pa400 .
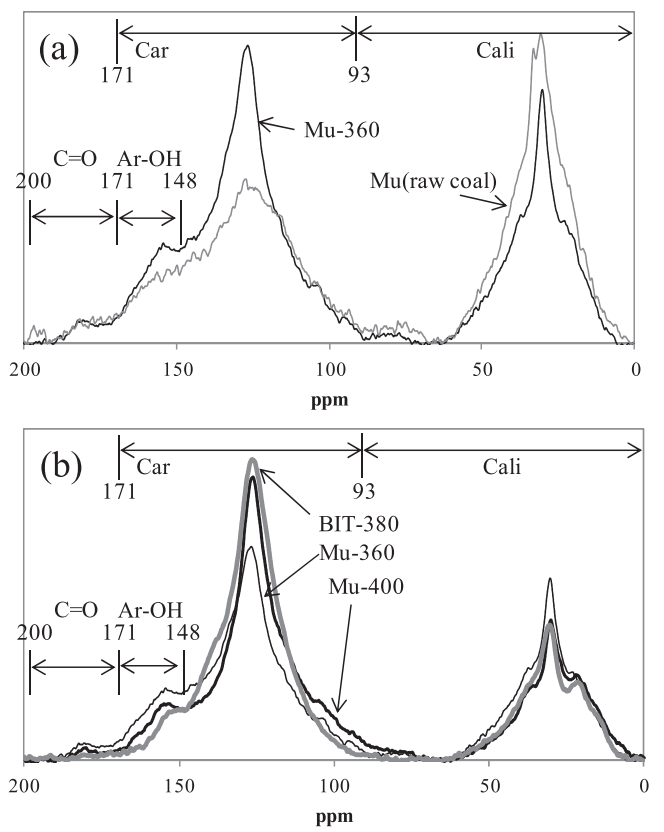

Fig. 5. Solid state ${ }^{13} \mathrm{C}-\mathrm{NMR}$ spectrum (a)comparison of Mulia coal with Mu-360 (b)comparison of BIT-380, Mu-360 and Mu400 .

\subsubsection{Structural Parameter}

The several structural parameters were calculated by using ultimate analysis, hydrogen/oxygen type distribution, and aromatic carbon ratio $\left(f_{a}\right)$ which was measured by solid state ${ }^{13} \mathrm{C}-\mathrm{NMR}$ or by the modified Brown-Ladner method for room-temperature extracts.

For the calculation, structural analysis program proposed by Sato ${ }^{10)}$ was used. Here it was assumed that all of sulfur type was thiophene, and for nitrogen, on the basis of the result of $\mathrm{Pa}-360$ by XPS, ${ }^{11)} 25 \%$ was pyridine ring, $75 \%$ was pyrrole ring and there was no quaternary nitrogen. Table 6 shows main structural parameters per unit structure; the
Table 5. Oxygen type distribution and number of oxygen type per 100 carbons.

\begin{tabular}{ccccccccc}
\hline \multirow{2}{*}{ Sample } & \multicolumn{3}{c}{ Oxygen fraction [\%] } & & \multicolumn{3}{c}{$\begin{array}{c}\text { Number of Oxygen } \\
{[-/ 100 \text { Carbons }]}\end{array}$} \\
\cline { 2 - 4 } \cline { 7 - 8 } \cline { 6 - 8 } & COOH & Ar-OH & -O-(diff.) & & COOH & Ar-OH & - -O-(diff.) \\
\hline BIT-380 & 19.8 & 80.2 & 0.0 & & 1.0 & 3.9 & 0.0 \\
\hline Mu-RT* & 27.4 & 44.2 & 28.4 & & 5.4 & 8.7 & 5.6 \\
Mu-360 & 28.1 & 54.5 & 17.3 & & 4.9 & 9.5 & 3.0 \\
Mu-400 & 19.3 & 60.3 & 20.4 & & 2.6 & 8.1 & 2.8 \\
\hline Pa-RT* & 34.2 & 49.3 & 16.5 & & 7.4 & 10.6 & 3.6 \\
Pa-360 & 29.5 & 53.6 & 16.9 & & 4.4 & 8.0 & 2.5 \\
Pa-400 & 19.6 & 59.7 & 20.7 & & 2.5 & 7.6 & 2.6 \\
\hline
\end{tabular}

*Oxygen type of raw coal was applied

Table 6. Unit structure parameter of extracts.

\begin{tabular}{|c|c|c|c|c|c|c|c|c|c|}
\hline \multirow[t]{2}{*}{ Sample } & \multicolumn{2}{|c|}{$f_{a}( \pm 0.03)$} & \multirow[t]{2}{*}{$\mathrm{C}_{\mathrm{p}} / \mathrm{C}_{\mathrm{ar}}$} & \multirow[t]{2}{*}{$\mathrm{R}_{\mathrm{a}}$} & \multirow[t]{2}{*}{$\mathrm{R}_{\mathrm{na}}$} & \multirow[t]{2}{*}{$\sigma$} & \multicolumn{3}{|c|}{$\begin{array}{c}\text { Number of Heteroatom } \\
{[-/ 1 \text { unit }]}\end{array}$} \\
\hline & ${ }^{13} \mathrm{C}$ & ${ }^{1} \mathrm{H}$ & & & & & $\mathrm{N}$ & $\mathrm{S}$ & $\mathrm{O}$ \\
\hline BIT-380 & 0.71 & 0.76 & 0.60 & 4.6 & 1.5 & 0.35 & 0.4 & 0.1 & 1.1 \\
\hline Mu-RT & - & 0.45 & 0.97 & 1.1 & 1.0 & 0.72 & 0.2 & 0.0 & 3.7 \\
\hline $\mathrm{Mu}-360$ & 0.65 & 0.72 & 0.79 & 2.1 & 0.6 & 0.39 & 0.2 & 0.0 & 2.7 \\
\hline $\mathrm{Mu}-400$ & 0.69 & 0.76 & 0.64 & 2.9 & 0.6 & 0.35 & 0.3 & 0.1 & 2.4 \\
\hline Pa-RT & - & 0.52 & 0.83 & 1.8 & 1.8 & 0.82 & 0.3 & 0.1 & 5.2 \\
\hline $\mathrm{Pa}-360$ & 0.64 & 0.73 & 0.74 & 2.6 & 0.1 & 0.36 & 0.2 & 0.0 & 2.4 \\
\hline $\mathrm{Pa}-400$ & 0.70 & 0.78 & 0.69 & 2.7 & 0.4 & 0.32 & 0.3 & 0.1 & 2.1 \\
\hline
\end{tabular}

$\mathrm{C}_{\mathrm{p}}$ : Peripheral carbon number of aromatic rings

$\mathrm{C}_{\mathrm{ar}}$ : Carbon number of aromatic rings

$\mathrm{C}_{\mathrm{p}} / \mathrm{C}_{\mathrm{ar}}$ : Degree of aromatic ring condensation

$\mathrm{R}_{\mathrm{a}}$ : Number of Aromatic rings

$\mathrm{R}_{\text {na: Number of Naphthenic rings }}$

$\sigma$ : Degree of aromatic ring substitution

degree of aromatic ring condensation: $\mathrm{C}_{\mathrm{p}} / \mathrm{C}_{\mathrm{ar}}$, the number of aromatic rings: $R_{a}$, the number of naphthenic rings: $R_{n a}$, the degree of aromatic ring substitution: $\sigma$, the number of nitrogen, sulfur and oxygen. In here, unit structure means the average molecular structure composed of a fused aromatic ring and side chains.

$\mathrm{R}_{\mathrm{a}}$ for both coals was 1-2 at room temperature, and it increased to $2-3$ at $633 \mathrm{~K}$ extraction. Also $R_{n a}$ decreased from 1.8 to 0.1 for $\mathrm{Pa}$, from 1.0 to 0.6 for $\mathrm{Mu}$.

It was considered that the increase of $\mathrm{R}_{\mathrm{a}}$ at $633 \mathrm{~K}$ extraction was caused by the occurrence of aromatization reaction as well as the extraction of heavy components along with the increasing extraction yield. One possible chemical reaction may be aromatization reaction by dehydrogenation of naphthenic ring.

At $673 \mathrm{~K}$ extraction, $\mathrm{R}_{\mathrm{a}}$ increased to 2.7 for $\mathrm{Pa}$ and 2.9 for $\mathrm{Mu}$. It is estimated that at higher extraction temperature, heavier components were extracted and aromatization reaction progressed more.

\subsubsection{Average Molecular Structure}

Figure 6 shows the average molecular structure per unit structure satisfied with structural parameters. The percentage indicates the ratio of its presence for each. For BIT-380 it became peri-type structure with $4-5$ aromatic rings. As 


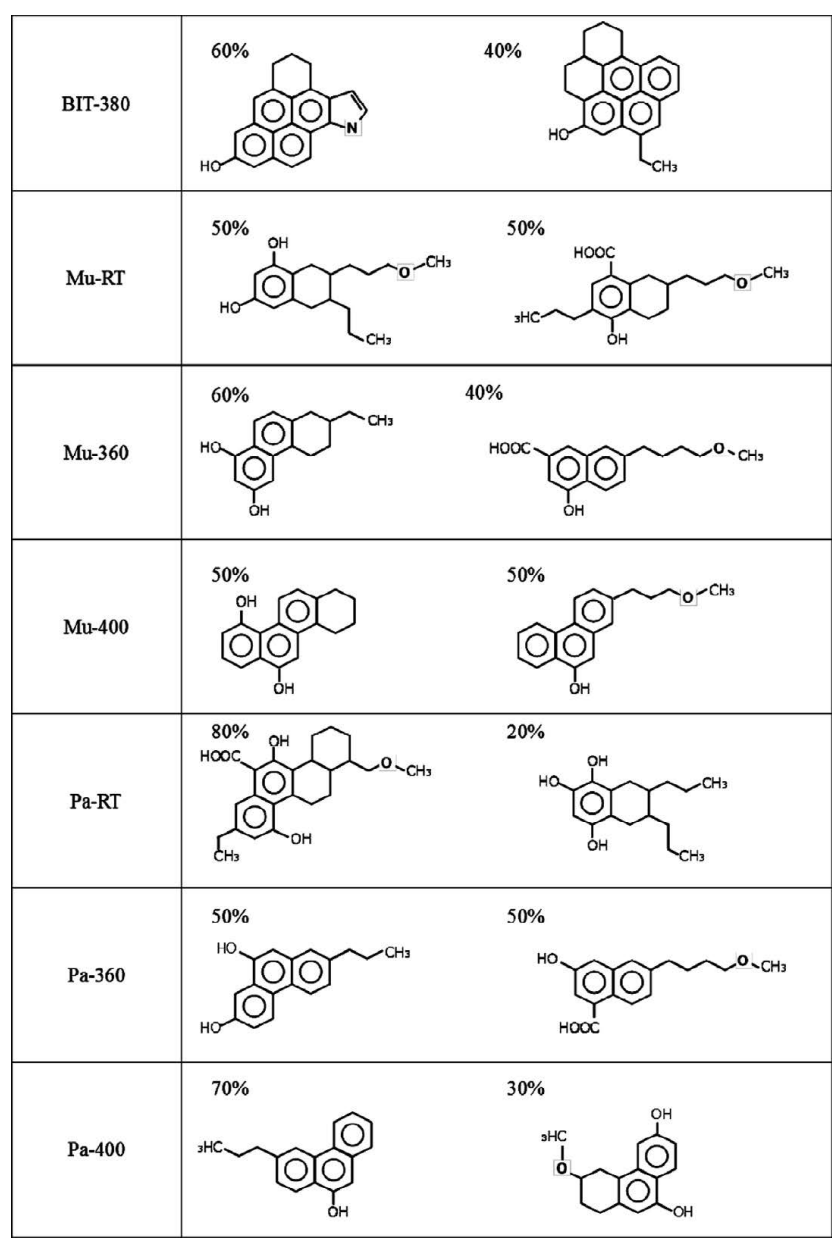

Fig. 6. Average molecular structure of extracts.

mentioned before, in case of model compounds, improvement of coke strength was observed from more than 4 rings and the effect was better in peri-type structure. ${ }^{5)}$ Thus, this result of structural analysis also indicates that BIT-380 has enough improvement effect for coke strength.

The room-temperature extract from $\mathrm{Mu}$ was consisted of 1 aromatic ring with relatively long side chains. At $633 \mathrm{~K}$ extraction, its $R_{a}$ increased to 2 and the length of side chain decreased.

The room-temperature extract from $\mathrm{Pa}$ had 1-2 aromatic rings, and the numbers of naphthenic ring and substituent groups was larger than Mu-RT. At $633 \mathrm{~K}$ extraction, $\mathrm{R}_{\text {na }}$ decreased and heavier component (2-3 aromatic rings) was obtained. Similar to $\mathrm{Mu}$, the decrease of oxygen and side chain was also confirmed. At $673 \mathrm{~K}$ extraction, the percentage of 3 rings increased and the length of side chain became shorter.

\subsection{Coke Strength}

Coke yield, shrinkage ratio and bulk density are shown in Fig. 7. The coke yield was decreased by adding HPC. The shrinkage ratio was decreased by adding Mu-360 or Pa-360. However, in case adding BIT-380, Mu-400 or Pa-400, the shrinkage ratio was increased. It is possible that coal plastic property was improved by adding BIT-380, Mu-400 and Pa400. The bulk density was decreased by adding HPC. This is because of the decrease of coke yield. However, comparing the effect of adding HPC extracted by $633 \mathrm{~K}$ with $673 \mathrm{~K}$
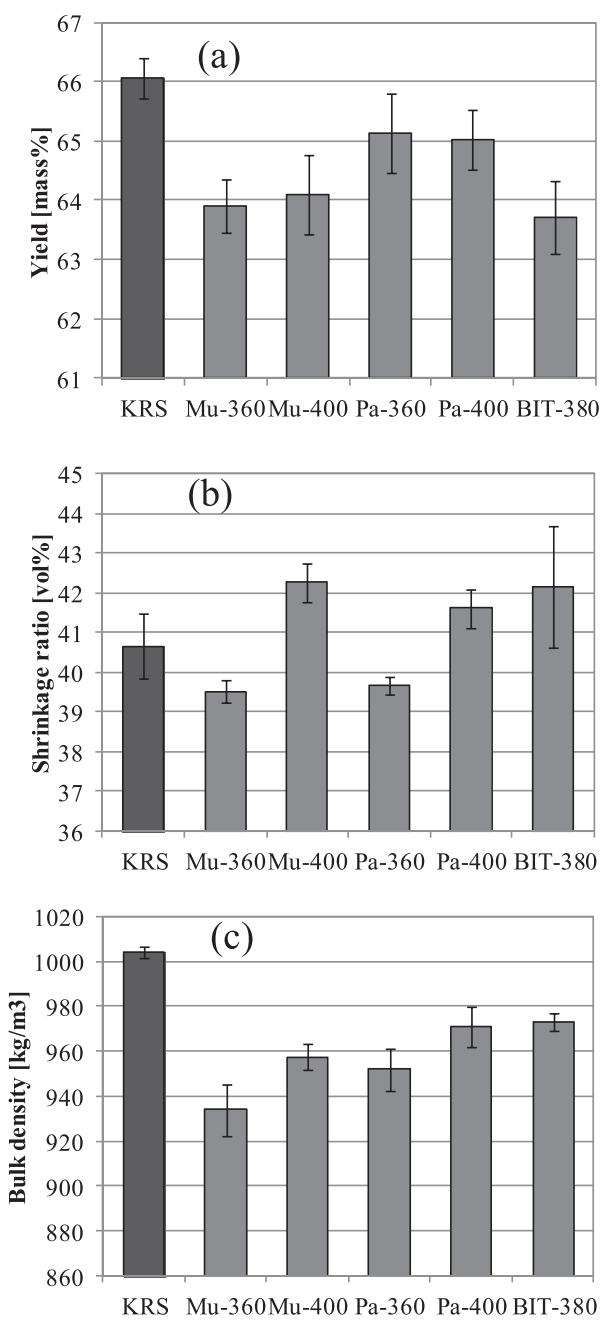

Fig. 7. Yield (a), shrinkage ratio (b) and bulk density (c) of the coke.

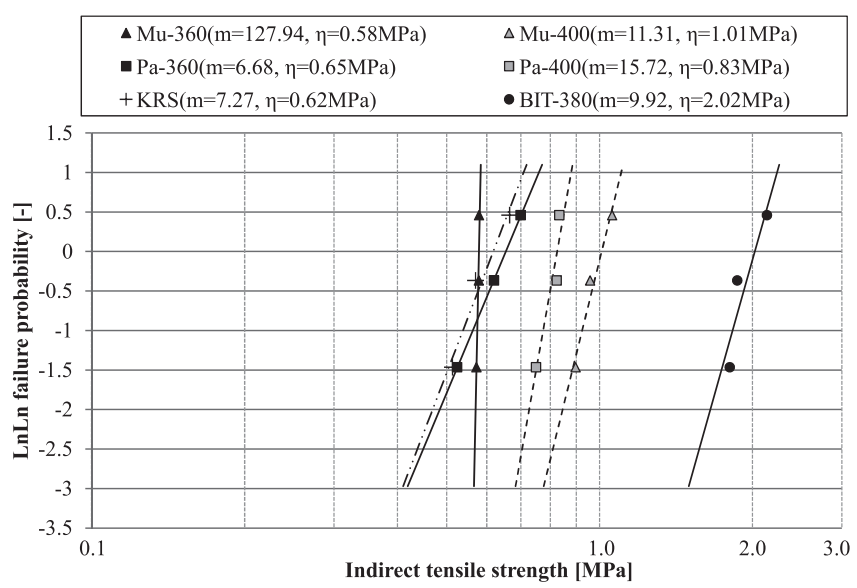

Fig. 8. Weibull plot of coke strength.

from the same low-rank coal, the coke yield became similar value, but the shrinkage ratio of coke adding HPC extracted at $673 \mathrm{~K}$ was higher than that at $633 \mathrm{~K}$. As a result, the bulk density of coke adding HPC extracted at $673 \mathrm{~K}$ was higher than that at $633 \mathrm{~K}$ and approached to that of coke adding BIT-380.

Weibull plot of coke indirect tensile strength is shown in Fig. 8. In this figure, $m$ represents coke strength dispersion 


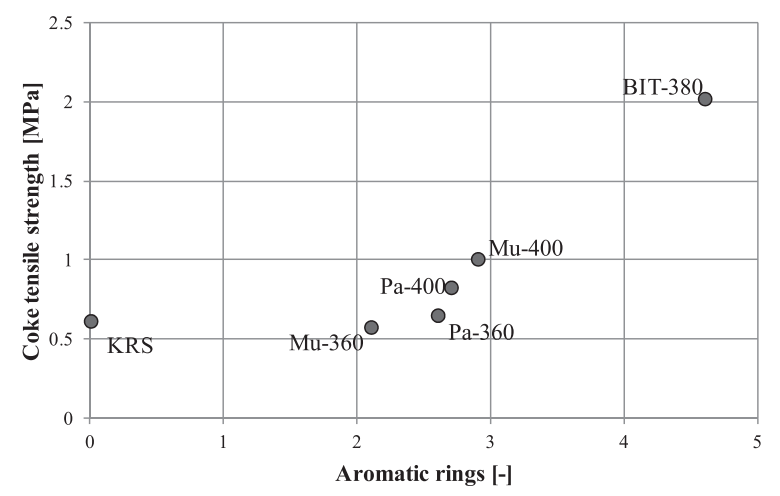

Fig. 9. Relationship between number of aromatic rings of additive and coke tensile strength $\eta$.

(higher value of $m$ means smaller dispersion) and $\eta$ is the representative coke indirect tensile strength (coke indirect tensile strength in case of cumulative crushing probability of $63.2 \%$ ). KRS coke was the standard coke sample and $\eta$ became $0.62 \mathrm{MPa}$. In case adding BIT-380, the coke strength was absolutely improved ( $\eta$ of coke added BIT-380 was $2.02 \mathrm{MPa}$ ). In case adding $\mathrm{HPC}$ extracted at $633 \mathrm{~K}$ (Mu-360 and Pa-360), the coke strength almost did not change. On the other hand, by adding HPC extracted at $673 \mathrm{~K}$ the coke strength was improved (Mu-400:1.01 MPa, Pa-400 : $0.83 \mathrm{MPa}$ )

The representative coke indirect tensile strength was plotted as a function of $\mathrm{R}_{\mathrm{a}}$ of added HPC, as shown in Fig. 9. Higher coke strength was obtained in case of higher $R_{a}$. It was indicated that the coke strength was influenced by $\mathrm{R}_{\mathrm{a}}$ of HPC. Similar result was reported in the previous study. ${ }^{5)}$ In that report, the coke strength was decreased by adding model compound which is consisted of less than 3 aromatic rings. In this work, $\mathrm{R}_{\mathrm{a}}$ of $\mathrm{Mu}-400$ and $\mathrm{Pa}-400$ was less than 3 , however, these additives improved the coke strength. Koyano et al. ${ }^{5)}$ reported that if molecular weight of additive is larger, its boiling point is higher, and much more fraction of poly-aromatic hydrocarbons should contribute to co-fusing. As a result, the additive improves the coal plastic property. In the current work, the unit average molecular structure of HPC was consisted of around 3 aromatic rings (as shown in Fig. 6). However, actual molecular structure is considered to be consisted of higher molecular-weight components connected by methylene and ether bonds etc.. Thus, even HPC composed of average rings of 2-3 may have significantly high boing point. Also, as shown in Figs. 4 and 5, since HPC has oxygen functional groups, those form hydrogen bonds easily, resulting in inhibition of volatilization of HPC itself. Furthermore, it was considered that the boiling point of HPC increased because the $R_{a}$ was increased with increasing extraction temperature. Takanohashi et l $^{2)}$ investigated the effect of extraction temperature on dynamic viscoelasticity of HPC produced form low-rank coal and reported that resolidification temperature of the HPC increased with increasing extraction temperature. Due to the above reasons, it was concluded that HPC produced from low-rank coals at $673 \mathrm{~K}$ improved the coke strength.

\section{Conclusion}

HPC produced from bituminous and low-rank coals was investigated by liquid state ${ }^{1} \mathrm{H}-\mathrm{NMR}$, solid state ${ }^{13} \mathrm{C}-\mathrm{NMR}$ and ultimate analysis. On the basis of these results, the average molecular structure was estimated and the effect of thermal solvent extraction on the chemical structure was investigated. Also, the strength of coke adding HPC produced from low-rank coals was measured to evaluate the effect of the chemical structure of HPC on coke strength. As a result, the following conclusions were obtained.

(1) Decarboxylation and aromatization reactions were occurred by $633 \mathrm{~K}$ and $673 \mathrm{~K}$ extractions for low-rank coals. Consequently, $f_{a}$ increased and $\mathrm{H} / \mathrm{C}$ and $\mathrm{O} / \mathrm{C}$ decreased, and then these parameters approached to HPC produced from bituminous coal.

(2) The average molecular structure of HPC was estimated. $\mathrm{R}_{\mathrm{a}}$ of HPC produced from bituminous coal was 4-5 and its molecular structure was peri-type. While, in case of low-rank coals, $\mathrm{R}_{\mathrm{a}}$ increased with the extraction temperature. $R_{a}$ of the extract obtained at room temperature and $633 \mathrm{~K}$ were consisted of 1-2 (Mu-RT : 1.1, Pa-RT : 1.8) and 2-3 (Mu-360 : 2.1, Pa-360 : 2.6), respectively. Also, when $\mathrm{HPC}$ was produced at $673 \mathrm{~K}$, the ratio of 3 aromatic rings increased.

(3) The coke strength increased with $R_{a}$ of HPC. In the previous study, the coke strength decreased by adding model compounds consisted of less than 3 aromatic rings. However, in this work, the coke strength increased by adding HPC which $\mathrm{R}_{\mathrm{a}}$ was less than 3 . It can be attributed to the difference in the boiling point. Since molecular weight of HPC can be larger than that of model compounds and HPC has oxygen functional groups, it is expected that even HPC composed of average rings of 2-3 has significantly high boing point. As a result, most of HPC remains in coke without volatilizing and contributes to improvement of coke strength.

\section{Acknowledgement}

This work has been done in Development of Cokemaking Technology from Low-grade and Nonconventional Carbon Resources, Division of High-Temperature Processes, Academic Society, the Iron and Steel Institute of Japan. The authors would like to acknowledge the research group members gratefully.

\section{REFERENCES}

1) T. Takanohashi and N. Okuyama: J. Jpn. Inst. Energy, 89 (2010), 7.

2) T. Takanohashi, T. Shishido and I. Saito: Energ. Fuel., 22 (2008), 1779.

3) T. Shishido, K. Sakai, N. Okuyama, M. Hamaguchi and N. Komatsu: Kobe Steel Eng. Rep., 60 (2010), 62.

4) K. Koyano, T. Takanohashi and I. Saito: Energ. Fuel., 25 (2011), 2565 .

5) K. Koyano, K. Ueoka, T. Takanohashi, K. Fukada and K. Ota: Tetsuto-Hagané, 96 (2010), 224.

6) J. P. Mathews and A. L. Chaffee: Fuel, 96 (2012), 1.

7) M. Sugano, S. Karino, M. Katoh, K. Hirano, K. Mashimo, K. Uebo and K. Masaki: Tetsu-to-Hagané, 96 (2010), 230.

8) T. Yoshida: Sekiyu Gakkaishi, 35 (1992), 1.

9) T. Miyagawa and I. Fujishima: J. Fuel Soc. Jpn., 54 (1975), 983.

10) S. Sato: J. Jpn. Inst. Energy, 90 (2011), 274.

11) H. Kawashima, K. Koyano and T. Takanohashi: Fuel Process. Technol., 106 (2012), 275. 